\title{
經濟研究所的工作和任務
}

一總路綫學習總結

狄超白

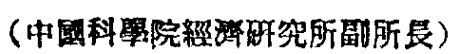

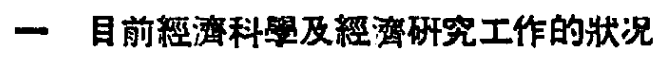

䟝目前篇止, 國內經㴒研究工作的力量是很 微弱的, 成就也很小。造與我椚黨領䢘全國人民 在草命第一階段及恢復時期對於垌會經涪所作的 巨大的改革及改造工作比較起來，㙷得極不相稱。 客新的原因是: 第一，在黨組樴颌導下的馬克思 列蜜主義經演研究工作者, 過去集中力量案加與

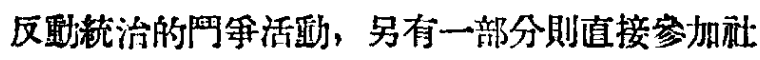

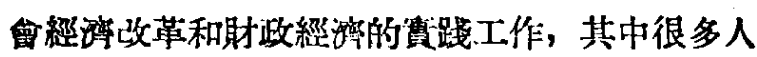
迄今還不能離開實践的岗位來玟力放研究工作。 第二，鹤時代具有進步倾问的但基本上仍是嚄民 主主義思想的經谇研究工作者, 他們在解放前得

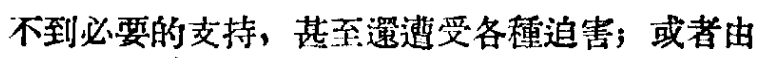
於他們只定静止地、孤立地研究問題, 收效不大,

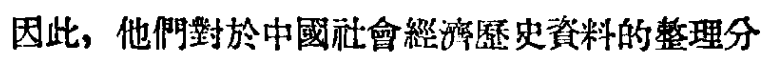
析以及革命前社會經济的媩查洌究踓會做了一 些，但亚没有完成初步的悬基工作。由於上进原 因, 過去國內經湾研究工作者在學術研究方面的

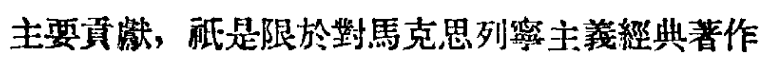

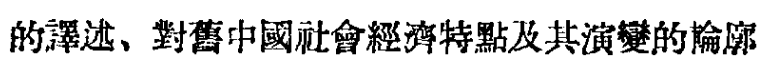
的分析、對反勁的經湾措施及言論進行理論的聞 孚以及新時代的紫蒙敉育等等方面, 而馬克思列

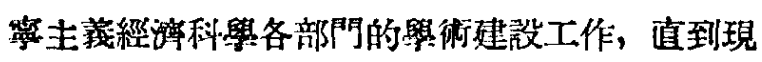
在子開始有條件來進行。

黨在過渡持期的德路棧和總任務對於經濟祭 研究工作的要求是繁重而迫切的。在思想効育的

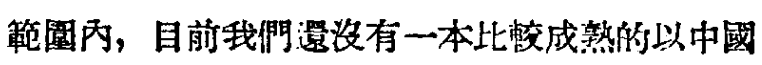

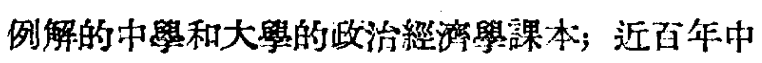

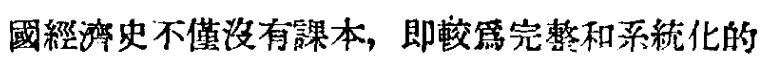

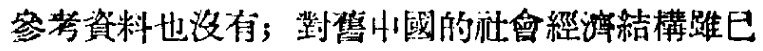
有一個輸潡的了解, 但還没有進行比較全面的系 統的研究; 三十年隶在全國範蒚內淮行了偉大的 土地改革渾動，但這些資料塄没有加以初步的整 理了具有極大現筫意義的在革命第一階段建立革 的根據地的財政䋑湾政策和設施, 也還沟有加以 初步的整理; 我國國声經洗恢復時期的成就，蘚

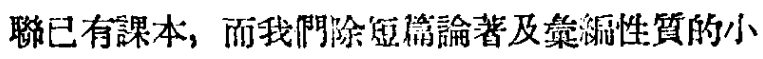
册子外，還沟有分部門的和綜合的饺第完整的著

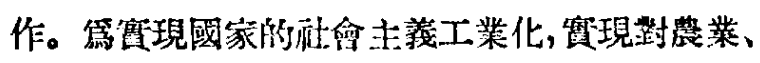
手工業和資本主義工商業的社會主義改造, 各業 務行政部門的工作幹部, 迫切需要從理論認識來

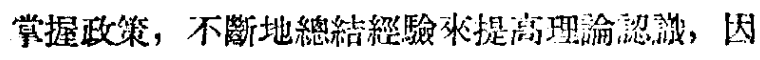

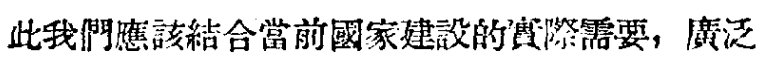
展開理論研究和學術討論。

逐步渋足上迅需要, 是至國經游工作者九其

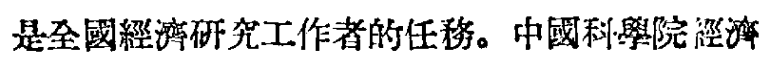
研究所目前主觀力量很微薄, 與目前的要求比較 起來, 相距很遠。

\section{二 穋齊研究所今後研究工作的發展輪廊}

郭沫若院長指出: 裳前利學工作的方針任移

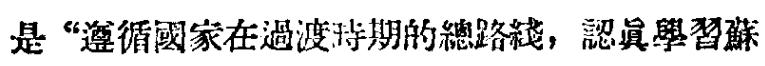

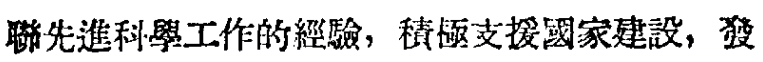

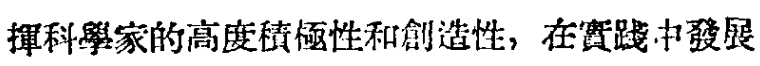

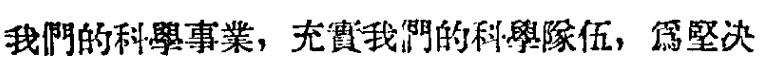
望現國家建設的總路綫和總任務而努力。”我椚本 着造一方針任務, 結合經泪研究所的具體情况,

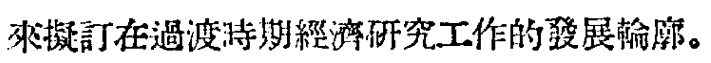

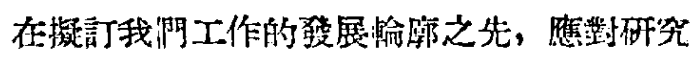

\section{9 月號}

科學涟報

- 27 - 


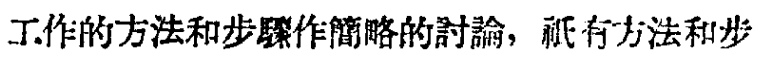

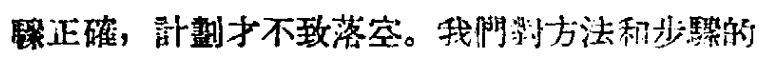
意胃歸納雼下列三點:

第一，一切工作都應鸽循黨在過湾時期的繦

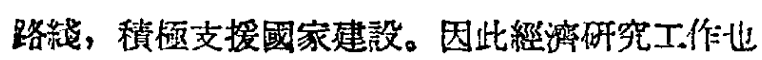
㮣密切結合社會主義的思想娃設工作和經汸衫建設 工作，在逐步貿現社會主義工業化和社會主䉝收

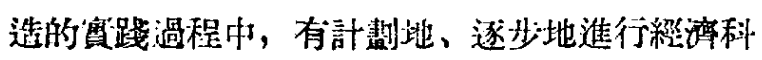
舅的學術都設。

第二, 經濟研究工作雔從独集資料和整理資 料故起。毛主席在論“改造我門的繁㚙”中锐道: “馬克思、恩格斯、列案、斯大林敉導我們說: 應賞從客觀存在着的貫際事物纳發, 從其中引出

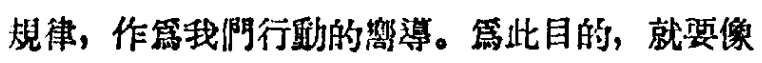
馬克思所設的詳細地佔有材料, 加以科學的分析 及綜合的研究。”“對於近百年的中國史, 㮣聚集人 材, 分工合作地去做, 克服無組織的狀態。㮣先 作經沙史……䋐倜部門的分析的研究, 然後才有 可能作綜合的研究。”這一指示基本上.規劃了一切 研究工作的過程和步踧, 也就是經濟研究工作的 過程和少睽。

第三，經沙研究所目前的工作人員很少，馬 克思列寧主義的理論修養還低, 對於社會主義建

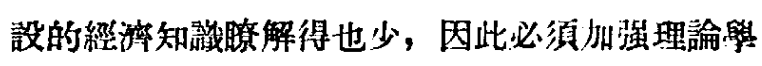

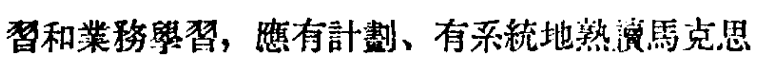
列蜜主的經典著作和毛主席的著作，而尤其重 要的是重視資践, 重視與業務部門的聯系, 在與 業務部門的共同工作中提任我門對社會主義建設

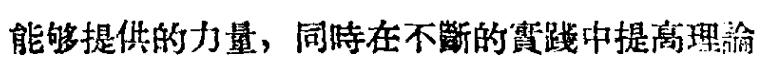
認識和增加業務知識。

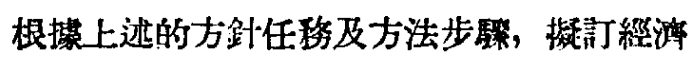
研究所的發琵輪廓如下:

（一）關於經濟理論及經泖問題的研究: 目 的在研究政治經濟學、社會主義經流建设理諭、 我國過渡時期的經濟理論; 並系統地落集、整理、

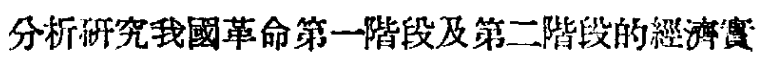

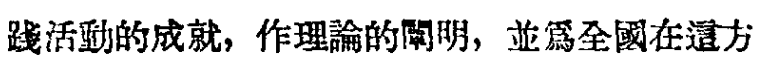

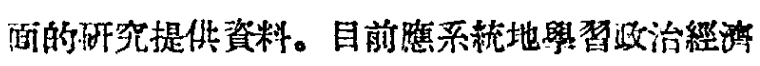

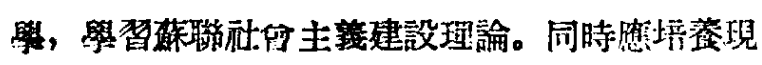
有的工作同志了解我國經湔的特點, 具借國印結: 就备部門一般的知識; 因此亦須從調查和蒐集資 料着手, 吸取感性知識蓝罢習正確的工作方法。

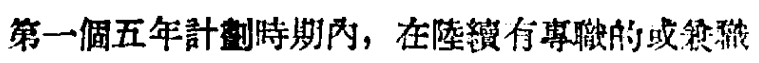
的高級研究人員㙁州的條件下，逐步分設：政治 經渓學、工業經济、宸業經源、貿易、財政金融、

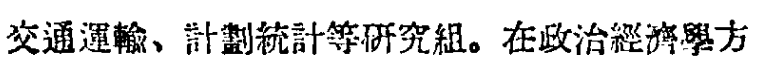
面, 隹作添統的研究, 间明過渡時期的經湾理諭,

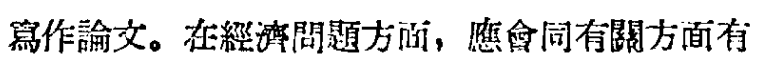
重點地逐步復集整理革命第一湝段解放澡財政䌦

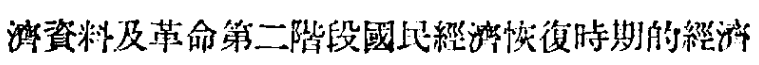

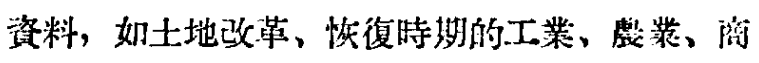

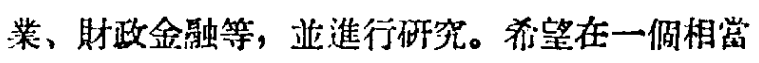
長的時期內能與有閵方面共闹進行上进网倜特期

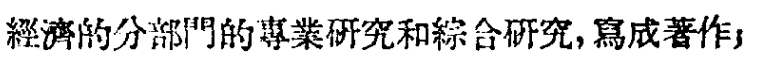

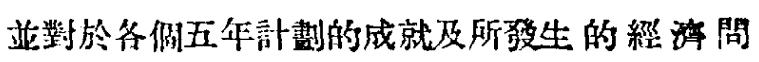
題, 淮行㸴究。

（二）關於近百年經游史的研究: 目的在系 䋇地全面地研究我國牛殖民地牛封建社會的性

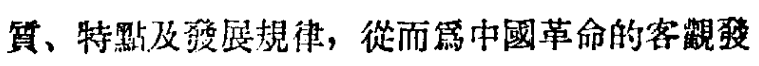
展過程及其特點的研究提供系緿的資料和科學的 論㨜。目前應先分門别類蕰集资料, 加以初步分 析, 作䈍大㽝敉學參考書籍, 並覀國內研究近百

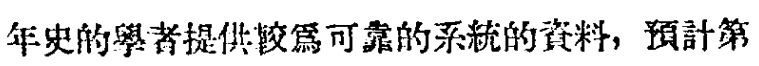
一個五.年計劃時期內完成此類资料著作若千種,

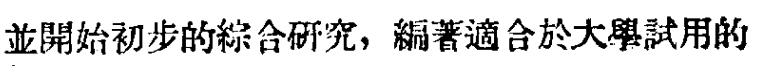
近百年經澋史棓本。五年以後, 進一步作分部門 的專業研究、專題研究和綜合研究, 完成更多的 軗業或曹題著作, 訂定近百年經湾史課本。

（三）關於社會主義生產力配置及經湾區都 問題的研究: 日的在我國社會主淺建設過程中,

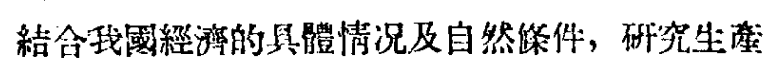

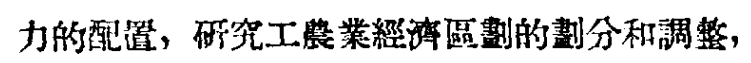
作䍃䋔濟建設工作的寥考。目前我們對誩方面的

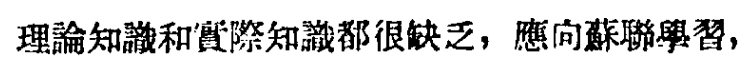

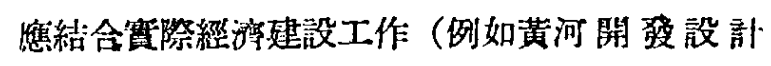

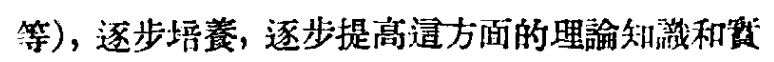

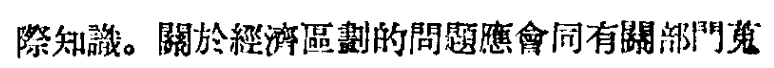
集資料共闹進行。這一力面的研究在五年之阿,

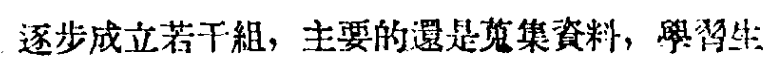

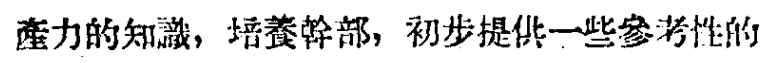
資料和意見。以後使我們在通方面的研究能逐少;

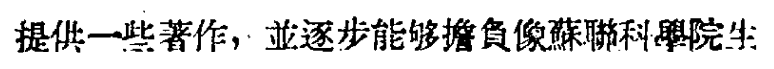
逶力委會中䋑浓研究部分的任務。

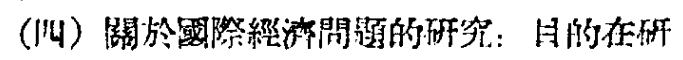




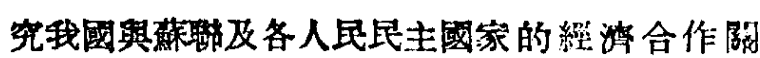
係，研究严洲各國的經濟情况及相不關係，研究 資本主義各國經学的狀况及發展超勢。國際經学

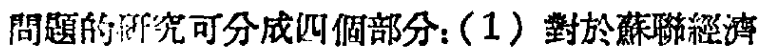
的研究；（2）對於各人民民主國家經沾的研究， （3）對於亞洲各國經㴼的研究；（4）龂於资本

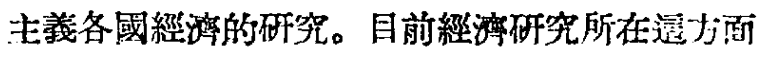
的研究須從頚做起。擬先配借少數人員從蒐集整 理資料做起，並會问有關方面分工合作進行。 $F$. 年之內, 主要在䓍集和慗理資料, 有系統地了解 各主要國家的基本經濟情况及相五經泻關係。首 先對亞洲或家的經濟進行系統的學晳和研究。有 重點地與有閔方面討論㸴究當前國際經游重要問 題，提仯一些寥考資料。五年以後可逐少按上述 14 储方面成立研究組, 從事專業及恧題著作。國 際經淬問題的研究, 不論是資料整理或著作, 都 應與嘗前的業務需要和政策需要密切緹合, 以適 虑過渡時期我國對外政治、經濟關係的各種 要 求。

（五）創辦一個定期的經济學研究刊物，刊 载學術論著、經渓資料、國內外著作介紹批評等， 並通過刊物絬系研究工作者。

\section{三一九五四年緾硣研究所工作計䁬}

（一）關於經滀問題的研究工作：本年队第， 一季度與中共中央農村工作部、國家梳計局等會 同緛輯手工業調查資料。第二季度寥加國家統計 同組織的手工業調查試點工作。第三季度寥加手 工業調查工作。第回季度整理資料和進行初步研 究。

（二）關於近百年經独史資料編朝工工作：本 年內開始䋧輯的計有工業史、農業史資料各网種, 手工業史、金融史、留易史、钽道史、航空史資 料各一種。預計本年內可完成的有网種。

（三）關於社會主義生烄力配置及經濟湂劃 的研究工作: 本年在院領導下寥加㣴河開墢設計 工工作，對於水成淹没損失及棉級開發進行學䅦，

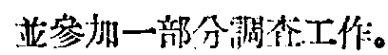

(四) 關於國際經娚的䃑究工作: 本年先配

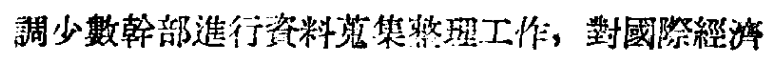

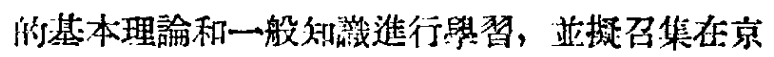
各有關毠位商砷分.工命作進行研究的辦法。舆行
罢術討諭會雨次玨三次。

(五) 關於出版經湒研究定期刊物：第二季

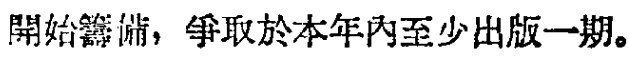

\section{四 與國內有關方面研究工作的聯系合作}

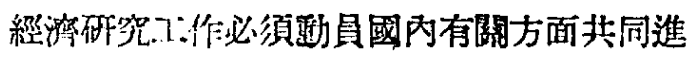

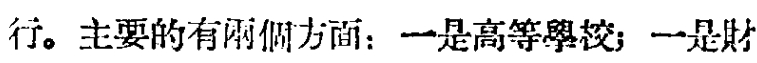

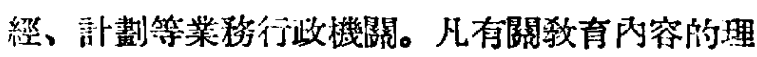

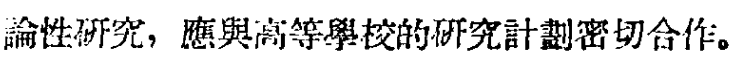

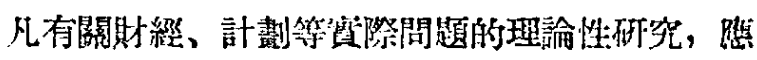
與各核菜務行政㭫閔密切聯系和結合。聯系合作 的辦法，首先應䚴企了解各高等學校的䂰究人員

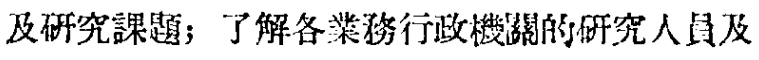

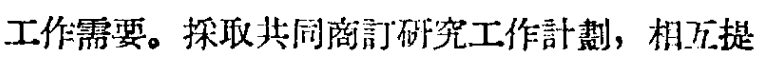
供資料, 以通訊、剖諭會等方式進行討論, 以及 相互象任工作等等。目前具體的步聚, 首先㮣了 解國內各經涔研究方酘的機棈、人員及研究工作 情况，提出初步的例究計劃及合作打法。

\section{五 習及幹部培鼠}

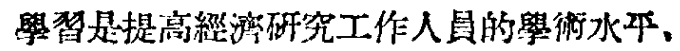
保登完成工作任伃的主要方法。在目前我阳研究

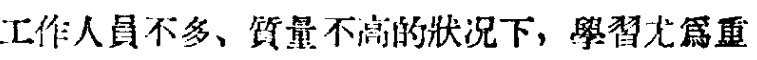

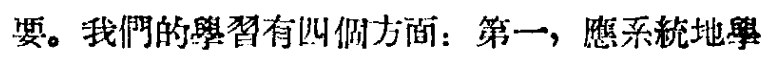

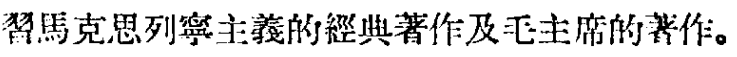

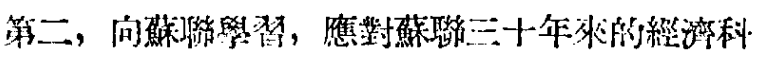

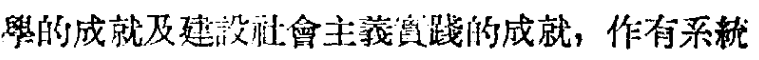

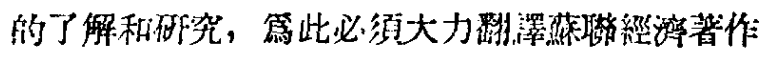
和開是俄文學栶。第三, 密切結合過渡時期的經

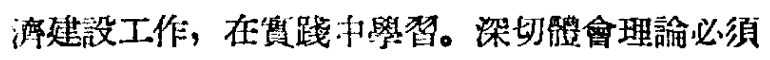
與實践密切結合的指示, 把理諭㲥用於資践, 並

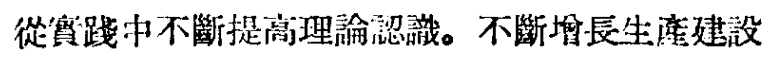

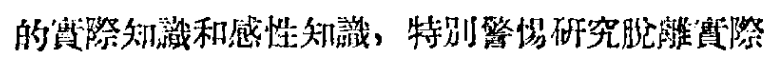
的傾间。第四，應與業務行政部門的沼究工作者

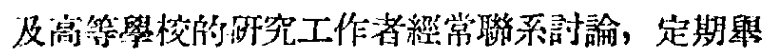

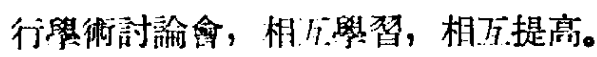

皘極培㥀新生力量, 摈大利學工作的榢伍與 後備力量, 應是經游研究機構的重琶任䅂之一。 每年焦吸收一定數量的優秀的㗅究生。對青年人

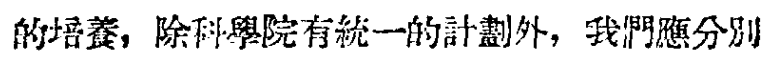
情况，指導他們以一部分特間寥加萝集資料、就

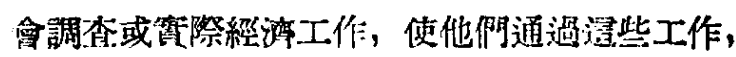




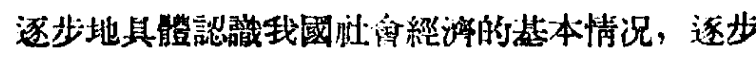

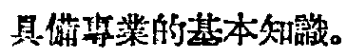

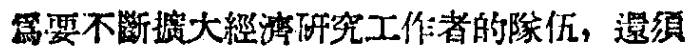

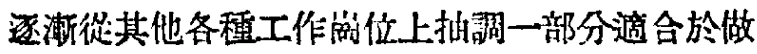
研究工作的人員来窑加破究工作。港本隊伍如不

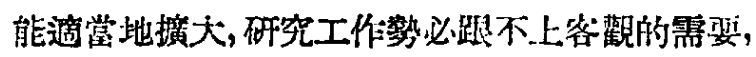

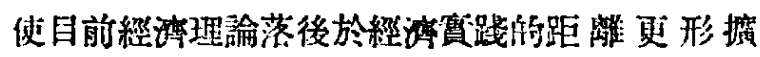
大，終至不利於經溜建設和文化建設。

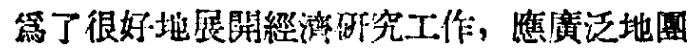

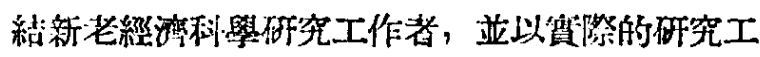

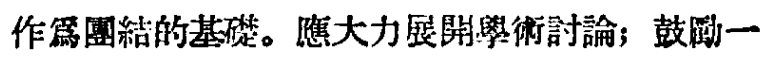
妡有研究工作能力的人員, 做專職的或業餘的研
究工作，亚分别情况，在汀能籍阔队給予济合於 他們的工作任䅂。

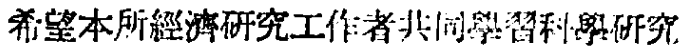

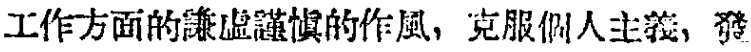
掦整體觀點和集體主䔐精神，應知迠建立融會言: 義的思想作風與副會主義的學術建没 是分 不開

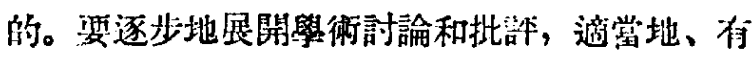
分寸地但是堅持不渝地提保學遇界的批弪和白我 批評的風氣，遭是蕀固我們的圈䋨，改進我椚的 思想作風，消隇缺點錯誤和推動鼠術進少的有效 武器。

\section{[上接 76 具]}

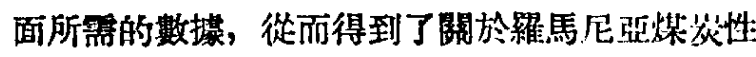
質的解釋，以及從熱力與化學技術的顴點看兆，

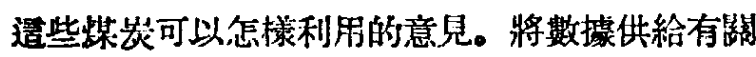
的研究所, 可使另一與燃燒固體燃料的_L㙯有閶 的問題 (即氣化維馬尼亞煤焱) 獲得解决。造将 有助於開探適宜於發生氣哑的原料。

研究所正面對着極篇重要的末來的任務 動力的研究, 其目的在於增加產量, 將較繁重的 然動機㖑化並且變得輕易，使勞動生產率很快的

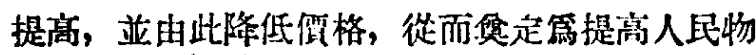
筫和文化水平所必需的技徖基礎。

孚了完成濖些偉大的目的，在最近的將來，

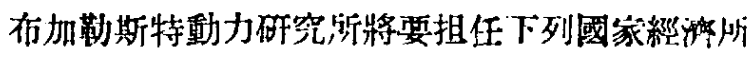
規定的問題的研究，這些問題包括：能源的合埋

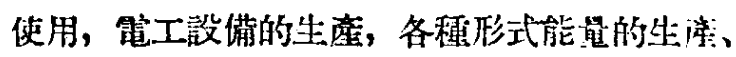
專撸、輸䢪與應用中所需没備的利片。以上這些 都是迫切的問題, 篇了解决逜些問題, 需要深入 的磁究和科學的棎討。

篮於峌力研究所不斷地加强着它與生産的聨

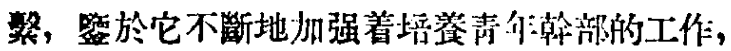
並且由於對擺在它证前問題作该深入确究的迫切

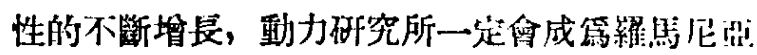

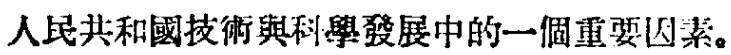
〔本刊特稿 唐統一 篎達川譯〕 